\title{
The rising trend in caesarean section rates: should we and can we reduce it?
}

\author{
Malik Goonewardene', D M A Kumara ${ }^{1}$, D R Jathun Arachchi ${ }^{1}$, R Vithanage ${ }^{2}$, R Wijeweera ${ }^{3}$
}

Sri Lanka Journal of Obstetrics and Gynaecology 2012; 34: 11-18

\begin{abstract}
Introduction: The rising caesarean section ( CS) rates in Sri Lanka are causing great concern.

Objective: To study whether it would be justified and feasible to attempt reducing the rising caesarean section (CS) rates at the Teaching Hospital, Mahamodara, Galle (THMG).
\end{abstract}

Method: Using the records available at the THMG, the trends in CS rates from 2007-2010 were studied. A prospective audit of CS was carried out in 2010, using a modified version of Robson's Ten Group Classification of Caesarean Sections.

Results: During 2007-2010 the mean CS rate in THMG has significantly increased, and fluctuated between $29.6 \%$ and $33.5 \%$, with no significant changes in perinatal morbidity and mortality, but with a significant increase in the proportion of mothers requiring intensive monitoring and intensive care. In 2010 the CS rates in THMG varied from $44.2 \%$ in Unit A, to $31.8 \%$ in the Academic Unit and $23.6 \%$ in Unit B. The main contributions to the high CS rates in the three units of the THMG were from the categories 5A and 5B (repeat CS), 2B (nulliparous term singleton vertex-NTSV, prior to the onset of labour), 1 (NTSV in spontaneous labour) and 2A (NTSV after induction of labour). The proportions in these categories varied significantly from one unit to another.

Conclusions: A detailed analysis of the indications for CS in each group in each of the units is required. The possibility of more nulliparous women and women with only one

\footnotetext{
${ }^{1}$ Academic Department of Obstetrics and Gynaecology,

${ }^{2}$ Unit $B$,

${ }^{3}$ Unit A, Teaching Hospital, Mahamodara, Galle, Sri Lanka.

Correspondence: Malik Goonewardene

E-mail:malikg@eureka.lk
}

previous CS scar and no other obstetric complication being carefully selected for a trial of vaginal birth should be explored. The possibility of pre-induction cervical ripening and careful selection of NTSV for induction of labour, and improving intrapartum management and the specificity of diagnosis of antepartum and intrapartum fetal distress needs to be explored. Reducing the high CS rates appears to be justified and feasible in THMG.

\section{Introduction}

There is great concern regarding the rising Caesarean Section (CS) rates in Sri Lanka ${ }^{1,2}$. The CS rates reported in Sri Lanka have increased from approximately $8.4 \%$ in $1988^{3}$ to $13.3 \%$ in $1998^{4}$ and $30.6 \%$ in $2007^{5}$ (Table 1). Globally, CS rates are estimated to vary from approx. $0.4 \%$ in Chad, Africa to $40 \%$ in China ${ }^{6,7}$. Higher CS rates are reported from private hospitals 8,9 , and in certain centres in Brazil, CS rates of $70-80 \%$ have been reported ${ }^{10}$. Globally, the increased rates of CS have been shown to be positively associated with maternal mortality and severe morbidity, even after adjusting for risk factors ${ }^{5,7,11-13}$. Therefore there should be a concerted effort to try and reduce the rising $\mathrm{CS}$ rates.

In order to address this issue of the increasing CS rates it is important to first carry out an audit to identify the indications and the factors which lead to CS. Robson's Ten Group Classification of Caesarean Sections could be used for this purpose ${ }^{14,15}$. In Robson's classification, all pregnant women are categorised in to ten prospectively determined, mutually exclusive, totally inclusive, and clinically relevant groups of women. In Sri Lanka, we have modified it by including sub divisions to some of these groups in order to facilitate easy analysis and comparison. These subdivisions are to separate CS after induction of labour (IOL) from CS prior to the onset of labour and CS after one previous CS from CS after more than one previous CS (Table 1).

Using this modified 10 groups of CS it is possible to study the indications and factors leading to CS in one unit during a particular period and compare the 
data prospectively as well as carry out comparisons with any other unit which has adopted this classification. This would enable audits and comparisons at local, regional, national and even international level. This would also enable each unit to decide whether its CS rate needs to be reduced and if so how it could be reduced.

Table 1. Caesarean section rates in Sri Lanka: $1988^{3}, 1998^{4}$, and $2007^{8}$

\begin{tabular}{lccc}
\hline Type of hospital & \multicolumn{3}{c}{ Caesarean section rate (\%) } \\
\cline { 2 - 4 } & 1988 & 1998 & 2007 \\
\hline Teaching hospitals & 12.7 & 22.7 & 32.5 \\
General hospitals & 9.3 & 20.3 & 25.4 \\
Base hospitals & 5.5 & 12.0 & 26.0 \\
Private hospitals & Not known & Not known & 66.6 \\
Total & 8.4 & 13.3 & 30.6 \\
\hline
\end{tabular}

Table 2. Modified ten groups of pregnant women

1. Nulliparous women with a single cephalic pregnancy, at greater than or equal to 37 weeks gestation, in spontaneous labour.

2. A) Nulliparous women with a single cephalic pregnancy, at greater than or equal to 37 weeks gestation, who have induction of labour.

B) Nulliparous women with a single cephalic pregnancy, at greater than or equal to 37 weeks gestation, who are delivered by caesarean section prior to the onset of labour.

3. Multiparous women, without a previous uterine scar, with a single cephalic pregnancy at greater than or equal to 37 weeks gestation, in spontaneous labour.

4. A) Multiparous women, without a previous uterine scar, with a single cephalic pregnancy at greater than or equal to 37 weeks gestation, who have induction of labour.

B) Multiparous women, without a previous uterine scar, with a single cephalic pregnancy at greater than or equal to 37 weeks gestation, who are delivered by caesarean section prior to the onset of labour.

5. A) Multiparous women, with one previous uterine scar and a single cephalic pregnancy at greater than or equal to 37 weeks gestation.

B) Multiparous women, with more than one previous uterine scar and a single cephalic pregnancy at greater than or equal to 37 weeks gestation.

6. Nulliparous women with single breech pregnancy.

7. A) Multiparous women with a single breech pregnancy, without previous uterine scar/s

B) Multiparous women with a single breech pregnancy, with previous uterine scar/s

8. A) Women with multiple pregnancies without previous uterine scar/s

B) Women with multiple pregnancies with previous uterine scar/s

9. A) Women with a single pregnancy with a transverse or oblique lie, without previous uterine scar/s

B) Women with a single pregnancy with transverse or oblique lie, with a previous uterine scar/s

10. A) Women with a single cephalic pregnancy at less than or equal to 36 weeks gestation, without previous uterine scar/s

B) Women with a single cephalic pregnancy at less than or equal to 36 weeks gestation, with previous uterine scar/s 
Teaching Hospital, Mahamodara, Galle (THMG) is a state managed tertiary care maternity and gynaecological hospital and it has three units. The objectives of this study were to compare the CS rates and the perinatal outcome among the three units of the THMG during the period 2007 to 2010 and compare the underlying factors leading to CS among the three and units of the THMG during the period 01st March to 31st December 2010. This could enable a reduction in the CS rates at the THMG, if appropriate and possible.

\section{Method}

The CS rates and the perinatal and maternal outcome in the THMG during the period 2007 - 2010 were analyzed using the Annual Hospital Statistical Bulletins of the THMG ${ }^{16}$. Using the modified 10 groups of CS the factors leading to CS, and the perinatal and maternal outcome were analyzed and compared among the three units, during the period 1st March - 31st December 2010.

\section{Results}

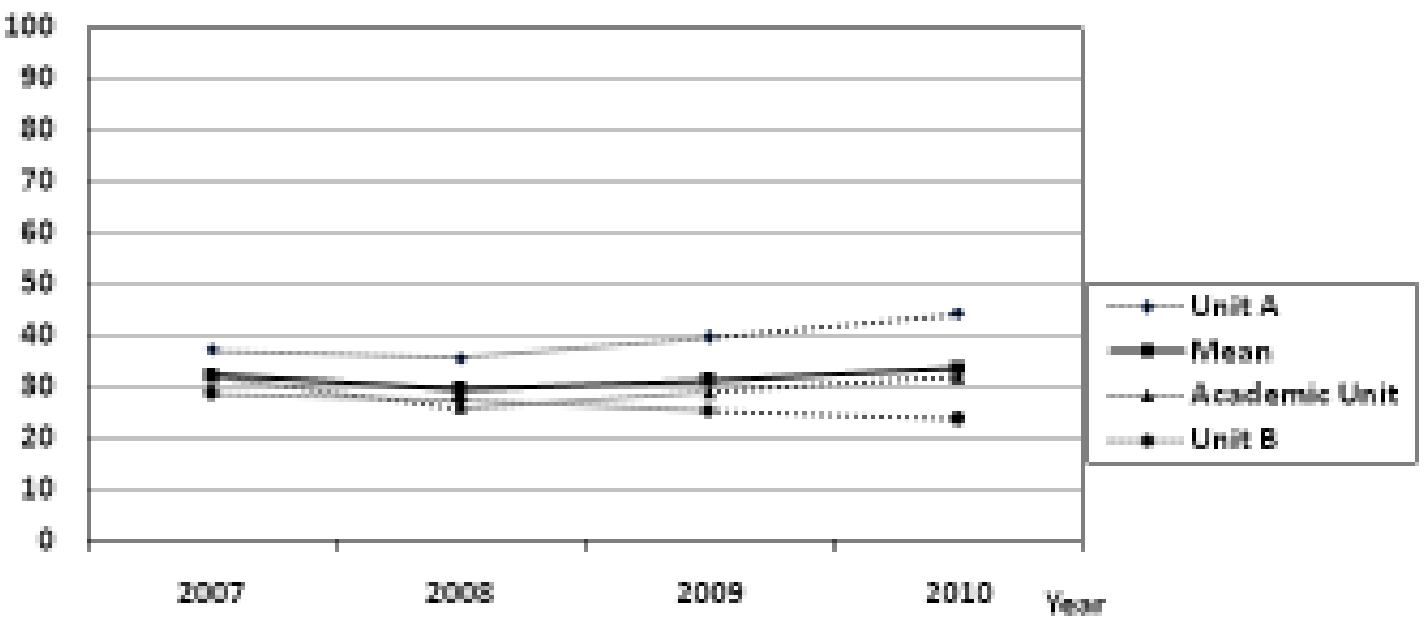

Figure. Caesarean section rates: $2007-2010^{16}$

The mean CS rate in the THMG has fluctuated between $29.6 \%$ and $33.5 \%$ during the period 2007 - 2010. In 2010 the CS rates in THMG varied from $44.2 \%$ in Unit A, to 31.8\% in the Academic Unit and $23.6 \%$ in Unit B (Figure 1) ${ }^{16}$.

Table 3. Modes of delivery: 2007 - 2010

\begin{tabular}{|c|c|c|c|c|c|}
\hline & 2007 & 2008 & 2009 & $\begin{array}{c}2010 \\
\text { (10 months) }\end{array}$ & $p$ \\
\hline Total deliveries & 14,704 & 14,310 & 12,405 & 9790 & - \\
\hline Normal vaginal deliveries $\%$ & 65.7 & 67.9 & 66.6 & 63.0 & $<0.001$ \\
\hline Caesarean sections \% & 32.3 & 29.6 & 31.2 & 33.6 & $<0.001$ \\
\hline Forceps deliveries $\%$ & 0.6 & 0.7 & 0.3 & 0.4 & $<0.001$ \\
\hline Vacuum deliveries \% & 0.8 & 1.0 & 1.1 & 1.2 & Not significant \\
\hline Assisted vaginal breech deliveries \% & 0.6 & 0.8 & 0.9 & 0.6 & $<0.05$ \\
\hline
\end{tabular}


During the period 2008 to 2010, there has been a significant increase of CS rates associated with a decrease of the proportion of normal vaginal deliveries, forceps deliveries, and assisted vaginal breech deliveries. The proportion of vacuum deliveries has not changed significantly (Table 3).

Table 4. Maternal and perinatal outcome: 2007 - 2010

\begin{tabular}{|c|c|c|c|c|c|}
\hline & 2007 & 2008 & 2009 & $\begin{array}{c}2010 \\
\text { (10 months) }\end{array}$ & $p$ \\
\hline Admission to special care baby unit $\%$ & 6.7 & 7.3 & 7.3 & 6.5 & $=0.05$ \\
\hline Still births/1000 deliveries & 7.3 & 8.2 & 7.7 & 7.2 & Not significant \\
\hline Perinatal mortality rate/1000 deliveries & 12.3 & 14.7 & 14.0 & 12.4 & Not significant \\
\hline Neonatal mortality rate/1000 live births & 4.9 & 6.4 & 6.3 & 6.1 & Not significant \\
\hline NND <28 weeks/1000 live births & 2.0 & 1.5 & 1.5 & 1.6 & Not significant \\
\hline $\begin{array}{l}\text { Maternal admissions for monitoring } \\
\text { or intensive care } \%\end{array}$ & 1.6 & 1.4 & 2.4 & 2.2 & $<0.001$ \\
\hline Maternal deaths & 4 & 11 & 4 & 2 & Not significant \\
\hline Total deliveries & 14,704 & 14,310 & 12,405 & 9790 & - \\
\hline
\end{tabular}

Admissions to the Special Care Baby Unit (SCBU) have shown a mild decrease with no significant changes in the perinatal outcome. The number of mothers requiring intensive monitoring or intensive care has shown a significant increase. Although the number of maternal deaths has increased in 2008, no significant trend was noted (Table 4).

Table 5. Modes of delivery: 2010

\begin{tabular}{|c|c|c|c|c|}
\hline & Unit $A$ & Academic Unit & Unit B & $p$ \\
\hline Total deliveries & 2853 & 4689 & 2248 & - \\
\hline Normal vaginal deliveries \% & 53.6 & 65.4 & 70.0 & $<0.001$ \\
\hline Caesarean sections \% & 44.3 & 31.8 & 25.8 & $<0.001$ \\
\hline Forceps deliveries \% & 0.1 & 0.6 & 0.4 & $<0.05$ \\
\hline Vacuum deliveries \% & 1.2 & 0.9 & 2.0 & $<0.05$ \\
\hline Assisted vaginal breech deliveries \% & 0.4 & 0.5 & 1.0 & $<0.05$ \\
\hline
\end{tabular}

In 2010, Unit B had the highest normal vaginal delivery (NVD) rate of $70 \%$ and the highest assisted vaginal breech delivery (AVBD) rate of $1 \%$ which were significantly greater than the NVD and AVBD rates in both the other units. Unit B also had the lowest CS rate of $25.8 \%$.

Unit A had the highest CS rate of $44.2 \%$ which was significantly greater than the CS rates in both the other units. The instrumental vaginal delivery rate in Unit A was also significantly less than in the other two units. 
Table 6. Maternal and perinatal outcome: 2010

\begin{tabular}{lcccc}
\hline & Unit A & Academic Unit & Unit B & $p$ \\
\hline Admission to special care baby unit $\%$ & 5.8 & 6.6 & 7.5 & $=0.05$ \\
Still births/1000 deliveries & 6.7 & 8.5 & 5.3 & Not significant \\
Perinatal mortality rate/1000 deliveries & 10.2 & 13.6 & 12.5 & Not significant \\
Neonatal mortality rate/1000 live births & 4.9 & 5.6 & 8.5 & Not significant \\
NND <28 weeks/1000 live births & 2.1 & 1.5 & 1.3 & Not significant \\
Maternal admissions for monitoring or intensive care \% & 1.9 & 2.0 & 3.2 & $<0.05$ \\
Maternal deaths & - & 1 & 1 & Not significant \\
Total deliveries & 2853 & 4689 & 2248 & - \\
\hline
\end{tabular}

In 2010, there were no significant differences between the units with regard to the perinatal outcome and the number of babies requiring admission to the Special Care Baby Unit (SCBU). However, there was a greater proportion of mothers requiring intensive monitoring or intensive care in Unit B.

Table 7. Main contributions to the high caesarean section rates in 2010

\begin{tabular}{|c|c|c|c|c|c|c|}
\hline \multicolumn{2}{|c|}{ Group } & \multirow{2}{*}{$\begin{array}{c}\text { Unit A } \\
333 / 335 \\
(99.4 \%) \\
p<0.001\end{array}$} & \multirow{2}{*}{$\begin{array}{c}\text { Academic Unit } \\
313 / 369 \\
(84.8 \%) \\
p<0.001\end{array}$} & \multirow{2}{*}{$\begin{array}{l}\text { Unit B } \\
57 / 126 \\
(45.2 \%)\end{array}$} & \multirow{2}{*}{$\begin{array}{c}\text { No of CS } \\
\begin{array}{c}703 / 830 \\
(84.7 \%)\end{array}\end{array}$} & \multirow{2}{*}{$\begin{array}{c}\% \text { of total CS } \\
21.4 \%\end{array}$} \\
\hline 5A. & $\begin{array}{l}\text { Multip, } 1 \text { previous scar, } \\
\text { single cephalic, > } 37 \text { weeks }\end{array}$ & & & & & \\
\hline $2 B$ & $\begin{array}{l}\text { Nullip, single cephalic, } \\
>37 \text { weeks, prior to onset } \\
\text { of labour }\end{array}$ & $\begin{array}{l}330 \\
(26.1 \% \text { of } \\
\text { Total CS) }\end{array}$ & $\begin{array}{c}212 \\
(14.2 \% \text { of } \\
\text { Total CS })\end{array}$ & $\begin{array}{l}74 \\
(12.8 \% \text { of } \\
\text { Total CS) }\end{array}$ & 616 & $18.8 \%$ \\
\hline $5 \mathrm{~B}$. & $\begin{array}{l}\text { Multip }>1 \text { previous scar, } \\
\text { single cephalic, }>37 \text { weeks }\end{array}$ & $\begin{array}{l}78 / 78 \\
(100 \%)\end{array}$ & $\begin{array}{c}146 / 169 \\
(86.3 \%)\end{array}$ & $\begin{array}{l}86 / 87 \\
(98.9 \%)\end{array}$ & $\begin{array}{c}310 / 334 \\
(92.8 \%)\end{array}$ & $9.4 \%$ \\
\hline 1. & $\begin{array}{l}\text { Nullip, single cephalic, } \\
>37 \text { weeks, in spontaneous } \\
\text { labour }\end{array}$ & $\begin{array}{l}91 / 597 \\
(15.2 \%)\end{array}$ & $\begin{array}{c}98 / 1095 \\
(8.9 \%) \\
p<0.001\end{array}$ & $\begin{array}{l}91 / 596 \\
(15.2 \%)\end{array}$ & $\begin{array}{c}280 / 2288 \\
(12.2 \%)\end{array}$ & $8.5 \%$ \\
\hline $2 \mathrm{~A}$. & $\begin{array}{l}\text { Nullip, single cephalic, } \\
>37 \text { weeks, who have } \\
\text { induction of labour }\end{array}$ & $\begin{array}{l}66 / 213 \\
(30.9 \%)\end{array}$ & $\begin{array}{c}160 / 554 \\
(28.9 \%)\end{array}$ & $\begin{array}{l}42 / 187 \\
(22.4 \%)\end{array}$ & $\begin{array}{c}268 / 954 \\
(28.1 \%)\end{array}$ & $8.2 \%$ \\
\hline
\end{tabular}

Group 5A: repeat CS after only one previous CS scar $(21.4 \%)$ was the leading contributor to the overall CS rate. There were marked differences in the successful VBACS rates in the three units: $54.8 \%$ in Unit B, $15.2 \%$ in the Academic Unit and $0.6 \%$ in Unit A. Group 2B: CS prior to the onset of labour in nulliparous women at term with a singleton vertex presentation (NTSV) had the second largest contribution (18 $8 \%$ ). This group contributed 26.1\% (Unit A), 14.2\% (Academic Unit) and 12.8\% (Unit B) to the overall CS rate. Group 5B: repeat CS after 2 or more previous CS, Group 1: emergency CS in NTSV after spontaneous onset of labour and Group 2A: emergency CS in NTSV after IOL, were the next three causes (Table 7). Of the 3289 who had a CS, 1164 belonged to the category of NTSV resulting in a CS rate of 35.4\% in NTSV. The CS rate in NTSV in Unit A (42.7\%) was markedly greater than the CS rates in NTSV in the other two units (25.3\% in the Academic Unit and $24.2 \%$ in Unit B). The Groups: 5A, 2B, 5B, 1 and 2A contributed $66.3 \%$ of the total CS carried out during this period. The contribution of the other groups is shown in Table 8 . 
Table 8. Contributions by the other groups to the high caesarean section rates in 2010

\begin{tabular}{|c|c|c|c|c|c|}
\hline Group & Unit $A$ & Academic Unit & Unit $B$ & No of CS & $\%$ of total CS \\
\hline $\begin{array}{l}\text { 4B. Multip at } \geq 37 \text { weeks, } \\
\text { prior to onset of labour }\end{array}$ & 125 & 87 & 61 & 273 & $8.3 \%$ \\
\hline $\begin{array}{l}\text { 10A. }<37 \text {, singleton vertex in nullip/ } \\
\text { multip without uterine scar }\end{array}$ & $\begin{array}{l}66 / 130 \\
(50.7 \%)\end{array}$ & $\begin{array}{l}90 / 158 \\
(56.9 \%)\end{array}$ & $\begin{array}{c}7 / 39 \\
(17.9 \%) \\
p<0.001\end{array}$ & $\begin{array}{c}163 / 327 \\
(49.8 \%)\end{array}$ & $5 \%$ \\
\hline $\begin{array}{l}\text { 3. Multip after spontaneous } \\
\text { onset of labour at }>37 \text { weeks }\end{array}$ & $\begin{array}{c}48 / 737 \\
(6.5 \%)\end{array}$ & $\begin{array}{c}56 / 1418 \\
(3.9 \%)\end{array}$ & $\begin{array}{c}31 / 713 \\
(4.3 \%)\end{array}$ & $\begin{array}{l}135 / 2868 \\
(4.7 \%)\end{array}$ & $4.1 \%$ \\
\hline $\begin{array}{l}\text { 4A. Multip after induction of } \\
\text { labour at }>37 \text { weeks }\end{array}$ & $\begin{array}{l}36 / 150 \\
(24.0 \%)\end{array}$ & $\begin{array}{l}74 / 303 \\
(24.4 \%)\end{array}$ & $\begin{array}{l}13 / 116 \\
(11.2 \%) \\
p<0.05\end{array}$ & $\begin{array}{c}123 / 569 \\
(21.6 \%)\end{array}$ & $3.7 \%$ \\
\hline 6. Primi breech & $\begin{array}{l}28 / 31 \\
(90.3 \%)\end{array}$ & $\begin{array}{l}77 / 97 \\
(79.3 \%)\end{array}$ & $\begin{array}{l}12 / 17 \\
(70.6 \%)\end{array}$ & $\begin{array}{c}117 / 145 \\
(80.7 \%)\end{array}$ & $3.6 \%$ \\
\hline 7A. Multi breech & $\begin{array}{c}25 / 31 \\
(80.6 \%)\end{array}$ & $\begin{array}{l}36 / 38 \\
(94.7 \%)\end{array}$ & $\begin{array}{c}3 / 20 \\
(15.0 \%) \\
p<0.001\end{array}$ & $\begin{array}{l}64 / 89 \\
(71.9 \%)\end{array}$ & $1.9 \%$ \\
\hline $\begin{array}{l}\text { All other groups } \\
7 B, 8 A, 8 B, 9 A, 9 B, 10 B\end{array}$ & $\begin{array}{l}39 / 47 \\
(82.9 \%)\end{array}$ & $\begin{array}{c}118 / 133 \\
(88.7 \%)\end{array}$ & $\begin{array}{c}53 / 97 \\
(54.6 \%) \\
p<0.001\end{array}$ & $\begin{array}{c}210 / 277 \\
(75.8 \%)\end{array}$ & $6.4 \%$ \\
\hline
\end{tabular}

Of the 3289 who had a CS, 531 were multiparous women who were at term with a singleton vertex presentation and no previous uterine scar, resulting in a CS rate of $14.3 \%$ in these women. The CS rate in this category of women in Unit A $(20.7 \%)$ was markedly greater than the CS rates in this category of women in the other two units $(12 \%$ in the Academic Unit and $11.8 \%$ in Unit B).

\section{Discussion}

This audit has identified the general characteristics and the pattern of the women who had a CS in THMG during 2010. The classification used for this preliminary audit of CS does not include the indications for carrying out CS. In order to establish whether it is justified and feasible to reduce the high CS rates in THMG, a further detailed analysis is needed of the underlying indications and factors which led to the CS in these women. This will enable an evaluation as to whether it is appropriate and feasible to attempt a reduction of CS in each particular group. If remedial measures are adopted with the objective of reducing the CS rates a re-audit in the same unit as well as comparisons between units will be useful to assess the outcome of implementation of such remedial measures.

The planned VBACS rate may vary widely from zero to $90 \%{ }^{17,18}$. The virtual absence of VBACS in Unit A reflects the policy in Unit A. Therefore the decision to carry out the primary CS especially in primigravidae should be taken with great care in Unit A, considering only definitely obstetric indications, to prevent a 'snow ball effect' and a further progressive increase of the already high CS rate. Although up to $76 \%$ of women with one previous CS may be able to successfully deliver vaginally ${ }^{19,20}$, up to $50 \%$ of them may decline consent for a vaginal birth after the caesarean section $(\mathrm{VBACS})^{21,22}$, and this will increase the repeat CS rate. In the presence of risk factors a planned VBACS may fail in up to $60 \%$ of cases. However, a previous vaginal birth and especially a previous successful VBACS is a very good predictor for successful VBACS and up to $90 \%$ of success have been reported ${ }^{23,24}$. In the Academic Unit, careful selection and motivation of more women with one previous CS to undergo a trial of VBACS is needed because a woman with two previous CS will not be permitted a trial of VBACS. 
During the last two decades there has been an increased number of CS carried out 'on demand', i.e at the patient's request and not on any justifiable obstetrics reason ${ }^{25,26}$. However, it has been clearly shown that this practice should be avoided as it is associated with increased maternal and perinatal adverse effects ${ }^{5,7}$. It has even been suggested that with evolution, human beings are developing a larger brain to think and having a narrow pelvis to move and natural selection is taking human beings towards more difficult childbirth, and human beings are becoming more intelligent enough to overcome this with $\mathrm{CS}^{27}$. It has also been found that up to $17 \%$ of Obstetricians (31\% female and $8 \%$ male) would opt for a CS for themselves or their partners in situations where there was no obstetric justification for the $\mathrm{CS}^{28}$. CS on demand has been shown to contribute up to $38 \%$ of the CS rate ${ }^{29}$, and significantly contribute to the rising CS rates $^{30}$. Approximately $17 \%$ of women in a study carried out in Southern Italy preferred elective CS and in approximately $91 \%$ of them the motivation for this choice was a perceived safer childbirth ${ }^{31}$. In a charitable non governmental hospital in Calcutta India, 99\% of women perceived CS to be safer for the baby than vaginal delivery, and $24 \%$ preferred CS to avoid labour pains $^{32}$. CS on demand will greatly increase the size of Group 2B. This will have a snowball effect and increase the size of Group 5 in the future. The Obstetrician should not become merely a technician carrying out the wishes of the woman and her partner. The Obstetrician has a duty to adequately discuss all the concerns of the woman and her partner regarding vaginal delivery, and counsel, advise and persuade them to accept and agree on the best obstetric management, on an individual basis.

The standard primipara 33 or the nulliparous term singleton vertex (NTSV) 34 is often used to compare CS rates between units. CS rates ranging from a low of $5.1 \%$ to a high of $34.2 \%$ have been reported ${ }^{15,34}$. In 2010, the indications and factors leading to the high CS rates in NTSV, a group of relatively low risk women, (Groups 1, 2A and 2 B in the current classification) need to be evaluated in all three units. The reason why the CS rate in NTSV in Unit A was approximately equal to the sum of the CS rates in the other two units, needs an in-depth analysis. A concerted effort is required to attempt a reduction of the high CS rate in NTSV prior to the inset of labour in Unit A and in NTSV after spontaneous onset of labour in Units A and $\mathrm{B}$. With proper selection of women, adequate pre induction cervical ripening of cervix, and the adoption of a good protocol and guideline for IOL, it may be possible to reduce the CS rate in Group 2A.

In multiparous women at term with a singleton vertex presentation and no previous uterine scar, the
CS rate in Unit A was approximately the sum of the rates of the other two units. Critical appraisal is required to identify the indications and the factors which led to the high CS rate in these apparently low risk multigravidae in Unit A.

With these in-depth analyses of the underlying factors and indications, and the adoption of appropriate remedial measures, a reduction of the high CS rates in the THMG should be feasible.

\section{Conclusion}

The general characteristics and the pattern of the women having CS have been identified. The reasons for the low rate of VBACS in Unit A and the Academic Unit needs to be critically appraised to assess the feasibility of increasing VBACS. The indications and the factors responsible for the high CS rates prior to the onset of labour in NTSV needs to be critically appraised in all three units and especially in Unit A, with a view to reducing if possible the CS rates in this group of women. The factors leading to CS after spontaneous labour in NTSV in Unit A and Unit B needs to be critically appraised to assess the feasibility of reducing CS in this group of women. The factors which lead to CS in multipara at term with a singleton vertex presentation also needs to be analyzed in all three units, especially Unit A. It appears to be justified and feasible to attempt reducing the rising CS rates at the THMG.

\section{References}

1. Goonewardene M, Gunaratna KA. Why are the caesarean section rates rising? Sri Lanka Journal of Obstetrics and Gynaecology 2001; 23: 20-27.

2. Gunasekera PC, Goonewardene IMR, Wijesinghe PS. The caesarean section rate is rising. Ceylon Medical Journal 2001; 46(iv): 147-50.

3. Fernando L, Abeywardene M. Trends in caesarean section. Sri Lanka Journal of Obstetrics and Gynaecology 1992-1993; 16: $14-20$.

4. Family Health Bureau. Annual Health Bulletin 1998. Ministry of Health, Colombo, Sri Lanka. 31

5. Lumbiganon $\mathrm{P}$, Laopaiboon M, Gulmezoglu AM, Souza JP, Taneepanichskul S, Ruyem P, Attygalle DE, et al. Methods of delivery and pregnancy outcomes in Asia: the WHO global survey on maternal and perinatal health 2007 - 2008. Lancet 2010; 375(9713): 490-9.

6. Bertran AP, Merialdi M, Lauer JA, Bing-Shun W, Thomas J, Van Look P, Wagner M. Rates of caesarean section: analysis of global, regional and national estimates. Paediatric Perinatal Epidemiology 2007; 21(2): 98-113.

7. Villar J, Valladares E, Wojdela D, Zavaleta N, Carroli G, Velazco A, et al of WHO 2005 Global Survey on Maternal and Perinatal Health Research Group. Caesarean delivery 
rates and pregnancy outcomes: The 2005 WHO global survey on maternal and perinatal health in Latin America. Lancet 2006; 367(9525): 1796-7.

8. Attygalle D. Global survey on maternal and perinatal health in Asia 2007-2008: Sri Lanka Country Report. Family Health Bureau, Ministry of Healthcare and Nutrition, Sri Lanka 2009.

9. Sreevidya S, Sathiyasekaran BWC. High caesarean rates in Madras (India): a population-based cross-sectional study. British Journal of Obstetrics and Gynaecology 2003; 110: $106-111$.

10. Barros FC, Vaughan JP, Victora CG, Huttly SRA. Epidemic of caesarean sections in Bazil. The Lancet 1991; 338: 167-9.

11. Kor-Anantakul O, Suwanrath C, Lim A, Chongsuviwatwong V. Comparing complications in intended vaginal and caesarean deliveries. Journal of Obstetrics and Gynaecology 2008; 28(1): 64-8.

12. Liu S, Liston RM, Joseph KS, Heaman M, Sauve R, Kramer MS. Maternal mortality and severe morbidity associated with low-risk planned caesarean delivery versus planned vaginal delivery at term. Canadian Medical Association Journal 2007; 176(4): 455-60.

13. Loverro G, Greco P, Vimercati A, Nicollardi V, VarcaccioGarofalo G, Selvaggi L. Maternal complications associated with caesarean section. Journal of Perinatal Medicine 2001; 29 (4): 322-6.

14. Robson MS. Can the high caesarean section rates be reduced? In: Recent Advances in Obstetrics and Gynaecology 22. Eds. Bonar J, Dunlop W. The Royal Society of Medicine Press Ltd. London 2004; 71-84.

15. Robson MS, Scudamore IW, Walsh SM. Using the medical audit cycle to reduce caesarean section rates. American Journal of Obstetrics and Gynecology 1996; 174 (1): 199-206.

16. Annual Hospital Statistical Bulletins, Teaching Hospital Mahamodara, Galle.

17. Bhasker K. Changing trends in caesarean section. In: Obstetrics and Gynaecology for Postgraduates Vol 1. Eds. Ratnam SS, Rao KB, Arulkumaran S. Orient Longman Ltd. Madras India 1992: 132-42.

18. Notzon Fe Plack PS,Taffed SM. Comparison of national caesarean section rates. New England Journal of Medicine 1987; 316: 386-9.

19. Guise JM, Berli M, McDonagh M, Osterwell P, Chan B, Helfand M. Safety of vaginal birth after caesarean section: a systematic review. Obstetrics and Gynaecology 2004; 103: 420-9.

20. Wen SW, Rusen ID, Walker M, Liston R, Kramer MS, Basker $\mathrm{T}$, et al. Comparison of maternal mortality and morbidity between trial of labour and elective caesarean section among women with previous caesarean delivery. American Journal of Obstetrics and Gynecology 2004; 191: 1263-9.
21. Lau TK, Wong SH, Li CY. A study of patients acceptance towards vaginal birth after caesarean section. Australian New Zealand Journal of Obstetrics and Gynaecology 1996; 36: 155-8.

22. McMohon MJ, Luther ER, Bowes WA, Olshan AF. Comparison of a trial of labour with an elective second caesarean section. New England Journal of Medicine 1996; 335: 689-95.

23. Royal College of Obstetricians and Gynaecologists. Greentop Guideline No. 45; February 2007: RCOG London .

24. Gregory KD, Korst LM, Fridman M, Shihady I, Broussard $P$, Fink A, et al. Vaginal birth after caesarean: clinical risk factors associated with adverse outcome. American Journal of Obstetrics and Gynecology 2008; 198: 452.

25. Turnbull D, Wilkinson CS, Yaser A, et al. Women's role and satisfaction in the decision to have a caesarean section. Medical Journal of Australia 1999; 170: 580-3.

26. Patterson-Brown S. Elective caesarean section - a woman's right to choose? In: Progress in Obstetrics and Gynaecology. Ed. Studd J. 2000; 14: 202-15.

27. Steer P. Caesarean section: an evolving procedure? British Journal of Obstetrics and Gynaecology 1998; 105: 1052-5.

28. Al-Mufti R, McCarthy A, Fisk NM. Survey of obstetricians' personal preference and discretionary practice. European Journal of Obstetrics and Gynaecology and Reproductive Biology 1997; 73: 1-4.

29. Jackson NV, Irvine LM. The influence of maternal request on the elective caesarean section rate. Journal of Obstetrics and Gynaecology 1998; 18: 115-9.

30. Coleman VH, Lawrence H, Schulkin J. Rising caesarean delivery rates: the impact of caesarean delivery on maternal request. Obstetrics and Gynaecology Survey 2009; 64(2): 1159.

31. Mancuso A, De Vivo A, Fanara G, Settineri S, Triolo O, Giacobbe A. Women's preference of mode of delivery in Southern Italy. Acta Obstetrics and Gynaecology Scandinavia 2006; 85(6): 694-9.

32. Hug I, Chattopadhyay C, Mitra GR, Kar Mahapatra RM, Schnieider MC. Maternal expectations and birth-related experiences: a survey of pregnant women of mixed parity from Calcutta, India. International Journal of Obstetrical Anaesthesiology 2008; 17(2): 112-7.

33. Cleary R, Beard RW, Chapele J, et al. The standard primipara as a basis for inter unit comparisons of maternity care. British Journal of Obstetrics and Gynaecology 1996; 103(3): 223-9.

34. Coonrod DV, Drachman D, Hobson P, Manriquez N. Nulliparous term singleton vertex caesarean delivery rates: institutional and individual level predictors. American Journal of Obstetrics and Gynecolgy 2008; 198: 694 e1-694 e11. 